\title{
DEBATE
}

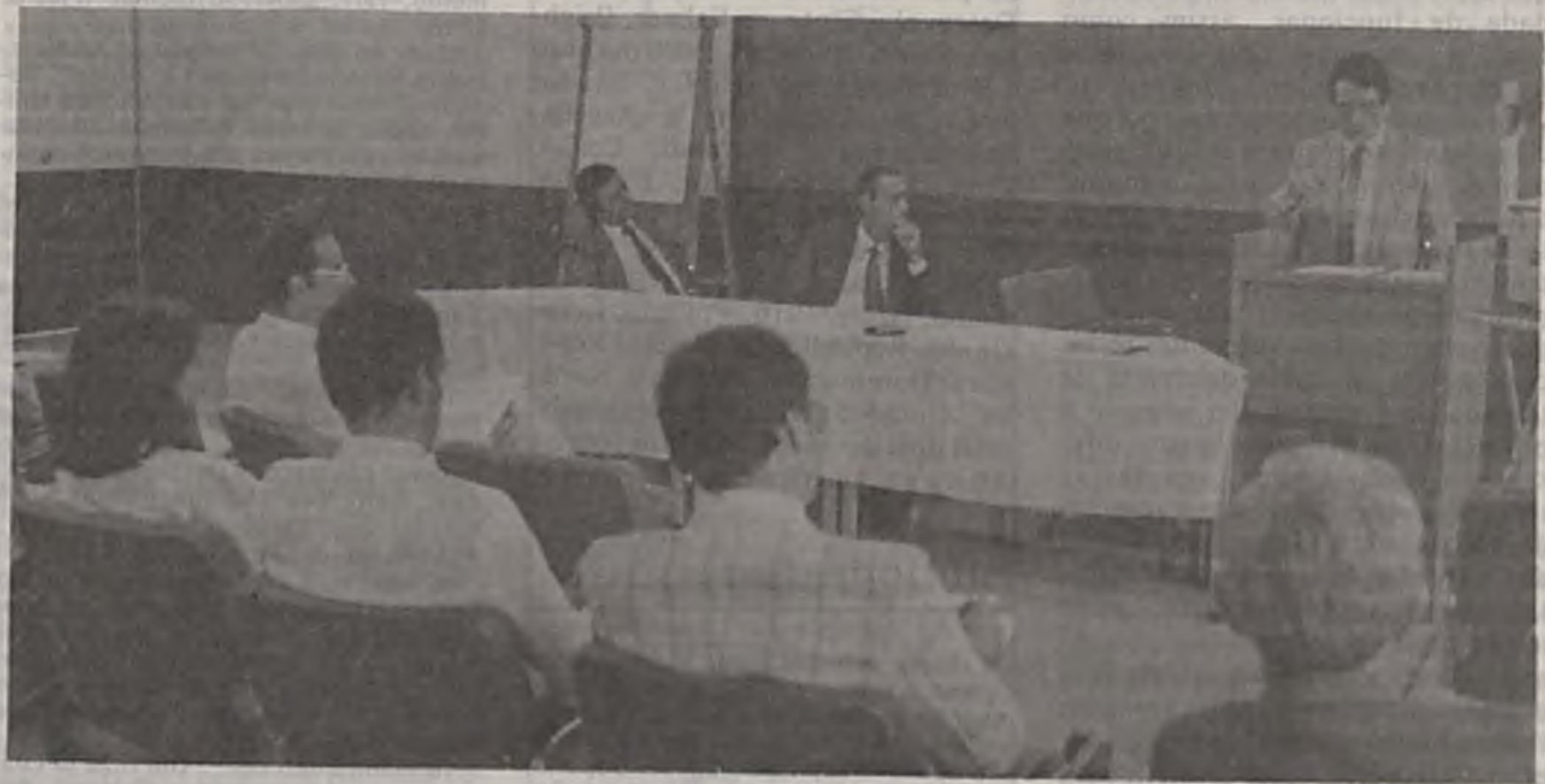

O presidente da Funcep, Paulo Catalano, presidiu os trabalhos

\section{Mudanças profundas no setor público só com a nova Carta}

1

ma reforma administrativa global, no Brasil, cstá ni dependência da nova Carta constitucional, a ser aprovada pela Constituinte. Sem esses dois fatos - a nova Constituiçào e a Reforma - nunca se chegará ao modelo de administração pública inerente à realidade da Nova República.

A Reforma poderia começar, por exemplo, pela extinçăo de vários organismos que nðo se enquadram mais na atual conjuntura politica $\mathrm{e}$ econômica. Mas decisōes desse porte nåo podem ser adotadas unilateralmente pelo Governo, sem ouvir a sociedade - no caso, o Congresso Nacional.

Essas posiçôes foram defendidas pelo secretário da Semor (Secretaria de Modernizaça e Reforma Administrativa), professor Sebastião Medeiros da Silva, durante o IV Seminário de Alualização da Administração Pública e de suas implica- cics, promovido pela Fundação Centro de Formação do Servidor P'ublico (Funcep).

Medciros revelou que há, hoje, no Brasil cerca de 20 mil órgãos na administraço direta e indireta, empregando um contingente em torno de 540 mil servidores, mais $170 \mathrm{mil}$ inativos e 136 mil pensionistas. Deste total, $126 \mathrm{mil}$ são estatutários, 410 mil são celetistas e os demais estão incluidos em outras modalidades.

A seu ver, além de optar pela extinção de algumas instituições que não se justificam mais hoje, o governo poderia pensar também na fusăo ou incorporação de outras unidades, como forma de evitar um problema social.

- Observamos que há um grande número de órgãos que não têm qualquer finalidade, atualmente - afirmou o secretário da Semor. Mas mudanças assim são inviáveis com a atual Constituição, porque há “um verdadeiro exagero de atos legais e regulamentares".

Medeiros lembrou que o Estatuto do Servidor é de 1952, o Plano de Classificação e Cargos tem mais de dez anos e o aparato legal, é uma espécie de camisa-de-força, um real inibidor das técnicas modernas de administraçao, pois não permite flexibilidade".

\section{MODERNIZAÇÃO}

Medeiros entende que o atual modelo de administração pública é arcaico. Dai a criação da Secretaria de Modernização e Reforma AdminisIrativa ter sido uma das fórmulas de conseguir traçar e executar um modelo que tenha a ver com a realidade do Pais.

O programa da Semor, segundo - Medeiros, visa, basicamente, a apoiar a Reforma, modernizar a administração do próprio Ministério e sustentar o Programa Nacional de 


\section{DEBATE}

Desburocratização, além de ajudar os Estados e Municipios em seus esforços de modernização.

- Precisamos de um modelo flexivel que seja capaz de atender as aspiraçōes da sociedade como um todo -- afirmou o secretário da Semor. É a primeira vez que, em nosso País, há preocupação com a viabilização da administração pública.

Para Medeiros, a Reforma é peça fundamental na restauração da cidadania, na democratização do processo administrativo, em sua descentralização, na revitalização do Serviço Público e na melhoria dos padrões de desenvolvimento, pela alocação eficiente dos recursos.

$O$ dirigente da Semor acredita, inclusive, que a reforma será o grande passo em direção à valorização do servidor, eliminando o grande desestimulo que impera nos quadros do Governo.

- Ao invés do aparato legal, que limita o poder de criação do servidor, defendemos a criação de uma lei orgânica na qual se fixem principios e que tenha a flexibilidade necessária para fazer cumpri-los.

Ao abrir o Seminário, o secretârio-geral do Ministério, Gileno Fernandes, analisou o clima que cerca, hoje, a Reforma Administrativa, identificando inclusive algumas mudanças que começam a ocorrer: principalmente de postura e comportamento do setor público como um todo.

- Mas falta mudar muita coisa, para as quais já temos linhas de açōes prioritárias - afirmou. Em seguida, enumerou as áreas por onde o Ministério pretende dar início à Reforma: estrutura operacional, desenvolvimento, recursos humanos e planejamento. Para isso, foram definidas medidas, por uma das câmaras da Reforma a serem tomadas a curto prazo em algumas dessas äreas.

As medidas de longo prazo passarão pela Constituinte, mas chegarão ao Presidente da República sob a forma de esboço. Ele as encaminhará ao Congresso. É o caso, por exemplo, da Lei Orgânica do Serviço Público, "uma espécie de Constiluição da Administração Federal", afirmou.

O secrelário-geral revelou que uma das idéias é transformar o Mi-

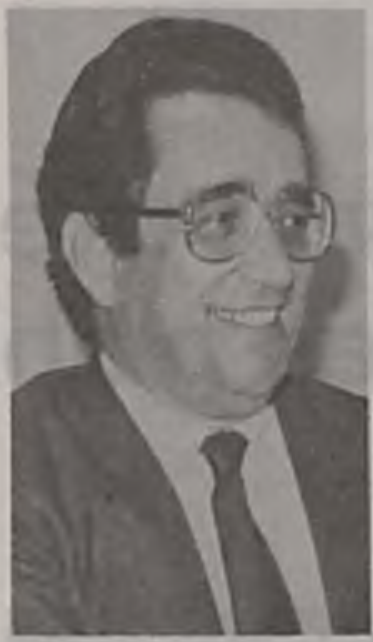

GILENO

Mudanças já

começaram

nistério da Administração e órgãos subordinados em geradores de idćias. E citou o plano de carreira como uma das propostas nesse sentido.

- Temos de contar com mecanismos mais eficazes - comentou, a certa altura de sua palestra de $48 \mathrm{mi}$ nutos. - E preciso traçar diretrizes para a área de recursos humanos, numa politica que envolve desde a extinção do Dasp (Departamento Administrativo do Serviço Público, criado cm 1939, no Estado Novo), até a informatização do Ministério.

O) secretário-geral insistiu numa tecla comum a todos os conferencistas do Seminário: é urgente a racionalização da máquina administrativa federal, atraves da fusão e incorporação de órgãos de funções semeIhantes, disciplina do emprego dos recursos, redefinição de instituições publicas c revisão organizacional e funcional.

- Nossa preocupação, na faixa dos recursos humanos, é com a valorização do servidor público, com a a formação de novos quadros de carreira; criar um sistema integrado de recursos humanos e promover o treinamento; por fim, adotar uma nova politica salarial.

Ao responder a perguntas do plenário, o secretário-geral da Administração reconheceu que a Reforma não está-se processando da forma rápida e eficaz como era de se esperar. E previu um prazo de pelo menos dois a nos para se chegar ao nivel renovação dos quadros de pessoal e

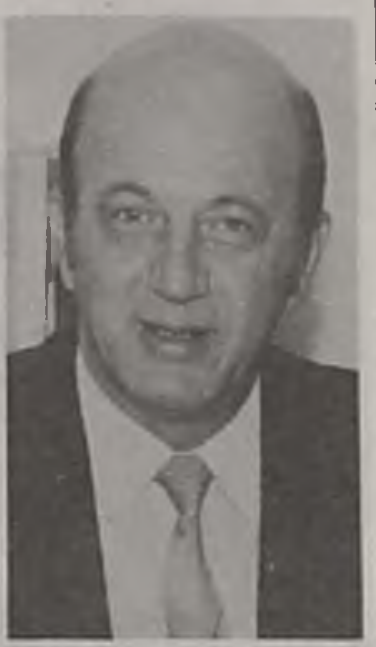

MEDEIROS

Constituinte

como marco ideal de reestruturação do serviço público federal.

- Na situação em que se encontra a Administração Pública brasileira - disse Gileno Fernandes - é até mais fácil adotar um plano de estabilização econômica, do que realiLar uma reforma administrativa.

Lembrou que a sociedade e o Presidente da República formam o universo dos que reclamam do emperramento da máquina administrativa federal.

Uma visão critica dos métodos e processos adotados para operar as mudanças na estrutura do serviço público federal foi oferecida pelo professor Jorge Viana Monteiro, lente de Economia da Pontificia Universidade Católica do Rio de Janeiro.

- Deve-se chamar de reforma organizacional o atual esforço do Governo, porque nào atende às finalidades que a própria administração central pretende atingir.

- O Pais precisa de uma reforma que traga profundas alteraçōes, capaz de atender às aspirações desperladas na sociedade com a reabertura do processo politico. Temos que acabar com os arranjos.

Outra via para chegar à Reforma, ainda de acorco com o professor da PUC-Rio, é acabar com a centralização administrativa, redução do grau de complexidade da estrutura governamental. E isto só é possivel, a seu ver, se dispuser de "teses criticas e de posiçōes inovadoras". 